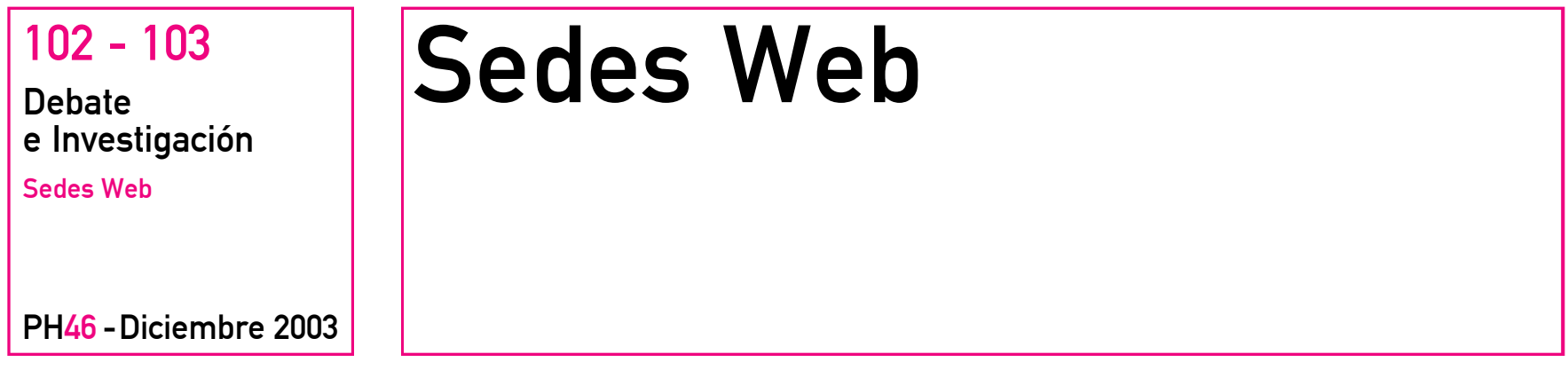

\title{
Patrimonio virtual: difusión del patrimonio cultural a través de Internet
}

En estos últimos años, estamos viviendo la llamada "convergencia digital", que debe apreciarse como un valor añadido para la difusión de la cultura en todas sus manifestaciones. El empleo de las nuevas tecnologias hipermedias aplicadas a la cultura visual es un fenómeno cada vez más reconocido y extendido en nuestra sociedad. Expresiones como sociedad de la información o era digital están cada vez más acuñados y ratifican transformaciones esenciales en la comunicación y el aprendizaje, y, en nuestro caso, en el conocimiento y difusión del patrimonio cultural en su más amplio sentido.

Asistimos a un concepto renovado de Patrimonio Cultural, que no se limita únicamente a museos y monumentos históricos, sino que se potencia el objeto cultural como un concepto más amplio que engloba todas las manifestaciones culturales sea cual sea su naturaleza, promoviendo su recuperación como elemento de comunicación y poniéndolo al alcance de todos.

La revolución digital en la sociedad del conocimiento implica un carácter más multidisciplinar del concepto "cultura", que lleva como máximo objetivo una implicación activa del usuario, que, a través de una estructura interactiva, es invitado no sólo a ver o indagar, sino a ser capaz de comparar, analizar e investigar.

Esta tendencia de cambio es algo que se está produciendo a nivel internacional, como una apuesta global de producir innovación tecnológica en el ámbito cultural.

Las consecuencias de todo este cambio se aprecian a nivel económico y social, ya que nos encontramos ante una etapa de la humanidad que desarrolla una tecnología que favorece la comunicación y que incrementa la producción y consumo de información, implicando directamente al usuario como agente activo.

La integración del patrimonio cultural en la vida cotidiana a través del uso de la nuevas tecnologías, encuentra en el hipermedia un valor de desarrollo. Nos encontramos ante una nueva visión de la cultura, más cercana, amplia y amena que hace que el usuario se interese, participe y

se implique, gozando de una mayor compresión del fenómeno cultural.

El diseño interactivo de los contenidos en el hipermedia, no sólo debe considerarse como un soporte tecnológico, sino como un nuevo concepto y una renovación de la estética de siempre, de la narración y la comunicación. La innovación técnica debe estar en sintonía con la renovación de contenidos. Por ello, en este campo de acción resulta necesario y conveniente la colaboración de expertos en tecnologías con agentes profesionales de la difusión cultural.

La capacidad de las tecnologías de la información a la hora de transmitir el conocimiento de la cultura, puede por ejemplo lograr que visitemos un templo egipcio, o la mezquita de Córdoba sin movernos de casa, o hacer más amena la transmisión de textos literarios o de pasajes históricos. Se pueden revivir paseos por monumentos históricos o reconstruir monumentos desaparecidos.

La realidad virtual lo hace posible, pero todavía la presencia de ésta en Internet es baja, predominando lo hipertextual frente a lo hipermedia.

Hasta hace poco, todas las empresas e instituciones tenían entre sus objetivos la presencia en Internet. La masificación de la red ha marcado un nuevo objetivo: conseguir ser visitados por el mayor número de usuarios posibles, desarrollando contenidos que atraigan al público, creando mundos virtuales que trasladen al visitante por recorridos atractivos, favoreciendo un mayor alcance de las imágenes, y animando así a que las personas visiten realmente aquel museo que les ha impresionado en Internet, o que se compren aquel libro que les ha sido mostrado con tanto acierto.

En nuestra reflexión sobre el alcance y repercusión de este cambio, llegamos a detectar distintos niveles de implicación en la difusión del patrimonio cultura a través de Internet.

Esta abarca diversos grupos de acción en este ámbito:

$>$ Portales temáticos de amplia cobertura donde se recoge toda la oferta cultural del momento $>$ Recorridos turísticos interactivos 


\footnotetext{
${ }^{1}$ Más información en la sección Proyectos y Experiencias, p. 85.

${ }^{2}$ Más información en la sección Proyectos y Experiencias, p. 84.
}

> Guías online para la promoción y enseñanza de la cultura

$>$ Redes nacionales e internacionales de museos e instituciones culturales

$>$ Fundaciones e instituciones científicas especializadas en la difusión del patrimonio cultural > Proyectos temáticos y nuevas plataformas de trabajo: encuentros, debates, herramientas, concursos...

> Nuevas plataformas de expresión artística

En la selección que recogemos en este número se muestran algunos ejemplos representativos de estos grupos, que pueden resultar de interés para el descubrimiento de la presencia en Internet de un amplio sector dedicado a la gestión y difusión de esta disciplina.

\section{Portales temáticos}

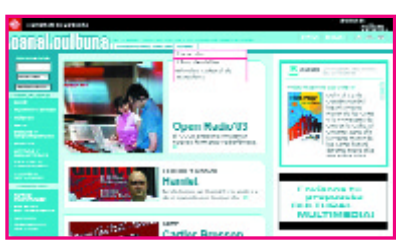

Canal Cultura

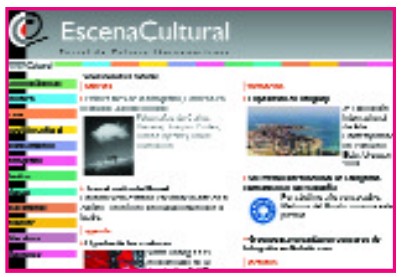

Escena Cultural

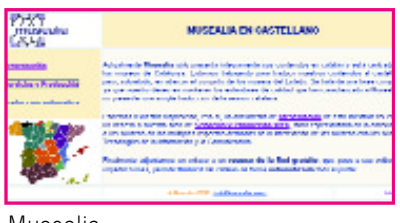

Musealia

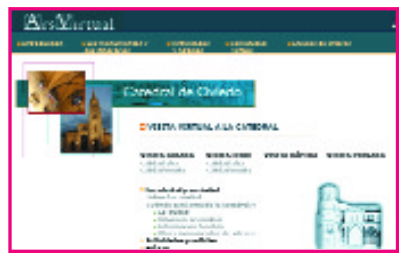

Catedral de Oviedo dos específicos: actualidad informativa con la oferta de cine, teatro, música, museos y bibliotecas, entre otros, así como servicios relacionados con rutas culturales, enlaces recomendados, agenda, comunidad cultural, etc. Cabe destacar la encuesta de opinión y la oferta a los usuarios de participar con propuestas culturales multimedia.

\section{EscenaCultural:}

portal de cultura iberoamericana

\section{http://www.escenacultural.com}

Estructurado igualmente con concepto de portal, presenta entre sus contenidos información relativa a: artes plásticas, música, cine, gestión cultural, pensamiento, fotografia, teatro, danza, patrimonio, folklore, literatura y flamenco dentro del ámbito iberoamericano, estructurado por países, y con foros, recomendaciones y otros servicios de interés para el usuario.

Musealia $^{2}$

http://www.musealia.com/

Musealia es un proyecto que busca explorar el nuevo espacio creado por el impacto de las Nuevas Tecnologías de la Información y la Comunicación (TIC) en el mundo de los museos, que en muchos aspectos es ciertamente una experiencia pionera en España.

Musealia tiene dos grandes ámbitos. De un lado mantiene el primer portal de Internet del pais dedicado de forma exclusiva a los museos, del otro se dedica a realizar tareas de consultoría y producción de proyectos web avanzados para instituciones gestoras del patrimonio, como museos y afines.

El portal web tiene a su vez también dos grandes apartados: el Profesional y el Público. En el primero se constituye un espacio de relación profesional entre los diferentes actores del sector museístico (contiene foros de debate, oferta de coproducciones e intercambios, presupuestos de proveedores online, directorios profesionales, gestión de invitaciones vía web, etc.). En el apartado público el usuario no profesional encuentra importante información sobre las propuestas de los museos de corte más "finalista" y de interés general (agenda de actividades y exposiciones, oferta educativa, extenso directorio editado de links sobre cultura y museos, etc.) pero con voluntad de conseguir un alto grado de interactividad mediante encuestas, foros, debates, boletín de novedades destacadas, etc.

\section{Recorridos turísticos interactivos}

\section{Catedral de Oviedo}

http://www.arsvirtual.com/monum/oviedo.htm Página Web desarrollada en un programa de realidad virtual denominado Ars Virtual que permite viajar por las ciudades de España y visitar aquellos monumentos que forman parte de nuestro Patrimonio artístico y cultural. Navegando a través de esta Web el usuario podrá conocer y adentrarse en cada unos de los monumentos artísticos que aqui se presentan.

Cada visita está establecida como una recreación lúdico - didáctica de forma que el visitante, además de disfrutar de ella, podrá conocer los aspectos más importantes de la historia del monumento así como acceder a información y fotografías de los diferentes elementos artísticos que hay dentro de cada monumento. 


\begin{tabular}{|l|}
\hline 104 - 105 \\
Debate \\
e Investigación \\
Sedes Web \\
PH46 - Diciembre 2003 \\
\hline
\end{tabular}

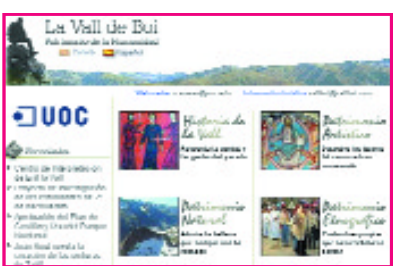

Vall de Boi

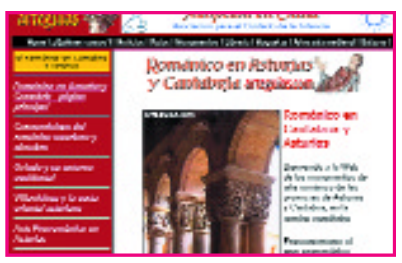

Arteguías

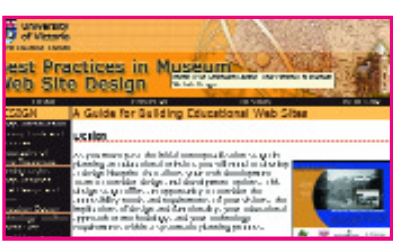

Musseum Web Site Design

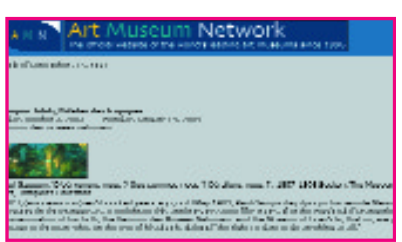

Art Museum Network

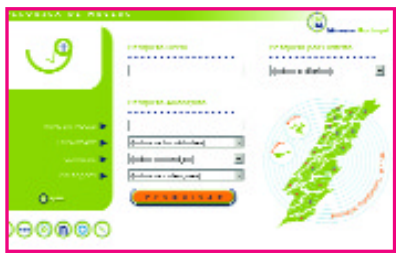

Museos Portugal
Se pueden destacar entre os elementos que presenta, cuatro modalidades de visita: Visita Guiada, Visita Libre, Visita Rápida y Visita Privada.

Además de la catedral de Oviedo, el proyecto ofrece visitas a otras catedrales y Reales Sitios, entre otros.

Vall de Boi

http://oliba.uoc.es/boi/portal/index_es.html El proyecto está centrado en la definición de una plataforma virtual para la difusión del patrimonio cultural y natural de una pequeña comunidad pirenaica alejada de los grandes centros tecnológicos y económicos de país. Permite presentar de forma virtual objetos y estructuras que hoy en día se localizan en Museos e Instituciones fuera del Vall, por lo que sirve para unir el patrimonio en un único lugar. Se entiende esta plataforma como un lugar de encuentro para los interesados en el románico y la historia medieval, un medio de comunicación para la comunidad local y un espacio educativo para estudiantes, visitantes y turistas

Guías online para la promoción y enseñanza de la cultura

Arteguias.com: Románico en Asturias

y Cantabria

http://www.arteguias.com/romanico_ cantabria_asturias.htm

Los autores de los contenidos de Arteguias promovieron varias páginas Web dedicados a rutas turisticas con el fin de dar a conocer el arte románico específico de Segovia y Ávila allá por mayo de 1999.

La respuesta fue positiva y en enero de 2002 ve la luz una nueva versión con orientación de portal que amplia su abanico a otros estilo medievales en España: mozárabe, mudéjar, gótico, etc.

En julio de 2003, tras el interés de los visitantes y la demanda de información sobre otros estilos y épocas de nuestro arte, se amplia la orientación de los contenidos al mundo antiguo y se aborda también el arte del Renacimiento. Arte- guias es además una forma alternativa de distribución de publicaciones sobre este estilo, que en ocasiones son difíciles de encontrar en librerías y posteriormente de maquetas de monumentos españoles y reproducciones artísticas medievales.

Best Practices in Museum Web Site Design http://www.uvcs.uvic.ca/crmp/ museumwebsites/

Esta sección alojada en la sede Web de la Universidad de Victoria en Canadá, explora las mejores prácticas en diseño de páginas Web para museos. Ofrece herramientas y recursos, modelos y ejemplos para profesionales de museos a considerar cuando se proyecte la construcción de una página Web con carácter formativo para el usuario.

Redes Nacionales e Internacionales de museos e instituciones culturales

Art Museum Network: sede Web oficial de los mejores museos de arte del mudo http://amn.org/index.shtml

Alberga, estructurado en cuatro secciones, toda la información disponible sobre: museos, colecciones, calendario de exposiciones y noticias sobre los museos. La plataforma de acción está centrada en Estados Unidos, sin olvidar enlazar con los principales museos de arte de Europa. Cuenta con herramientas de búsqueda por regiones y con una amplia vocación de comunicación entre todos los miembros.

Museos Portugal

\section{http://www.museusportugal.org/}

Es una iniciativa abierta a todos los profesionales e instituciones cuyo mayor objetivo sea el contribuir a una eficaz y completa integración de los museos portugueses en la Sociedad de la Información. Pretende ser una plataforma tecnológica que favorezca la comunicación entre los museos y sus profesionales y los museos y el público. Entre los contenidos que ofrece cabe señalar un potente sistema de búsqueda estructurado bien por accesos geográfico, o seleccionando localidades, servicios y temáticas, por separado o de forma conjunta. 


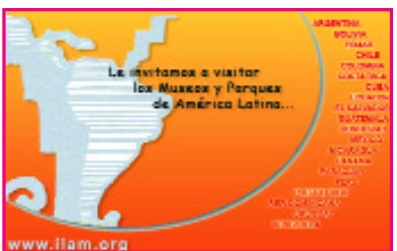

REdILAM

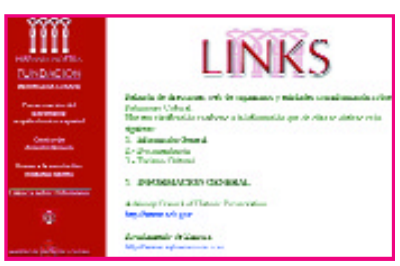

Fundación Hispania Nostra
RedILAM: red de museos y parques

de America latina

\section{http://www.ilam.org/}

Cuenta con varias secciones dedicadas a:

Agenda, el boletín bimestral del ILAM (Instituto Hispanoamericano de Museos), buscador, foros y vínculos, entre otros enlaces de interés. Además, al igual que en los caso anteriores se ofrece la búsqueda por países y un acceso geográfico a las instituciones albergadas de cada país miembro.

\section{Fundaciones e instituciones científicas especializadas en la difusión del patrimonio cultural}

Fundación Hispania Nostra:

conservación y puesta en valor del patrimonio cultural español

\section{http://www.hispanianostra.es}

Hispania Nostra es a su vez Asociación y Fundación. La Fundación, dirige su trabajo a promover, impulsar, coordinar y/o ejecutar actuaciones situadas en el marco de la llamada Conservación Integrada del Patrimonio.

Sus objetivos principales se integran en:

la Conservación Integrada del Patrimonio Arquitectónico, entendida no sólo como la restauración o mantenimiento de los elementos y conjuntos que lo integran, sino como una visión global que abarca tanto los aspectos culturales como los económicos y sociales, y la consideración efectiva del Patrimonio Cultural como un recurso productivo, capaz de desarrollar una gran potencialidad económica, fuente del turismo cultural y factor de desarrollo económico y social.

Acceso al conocimiento y uso del Patrimonio Cultural, y la difusión de su mensaje científico y pedagógico, como factor esencial de enriquecimiento individual y colectivo, y como medio imprescindible para conseguir la corresponsabilidad del sector privado en las tareas de la conservación.

La colaboración pública-privada como procedimiento idóneo para alcanzar la mayor eficiencia en las actuaciones en favor del Patrimonio Cultural.
En su página web destacan en otros contenidos un amplio directorio de recursos realcionados con el patrimonio.

\section{Centro Virtual Cervantes}

\section{http://cvc.cervantes.es}

Dentro de la misión de promocionar la cultura en español, el Instituto Cervantes, a través de su Centro Virtual ha puesto en marcha dos iniciativas principales: por un lado, la recuperación de espacios perdidos mediante el uso de la realidad virtual, como es el caso de la Mezquita de Córdoba omeya; por otro, la puesta en relieve de un patrimonio cultural esencial en la producción española del siglo XX, el museo virtual de arte publicitario. En su apuesta por la realidad virtual para poner en conocimiento las diversas disciplinas, cabe destacar también la visita al Salón de Reinos. Además, cuenta con un interesante recorrido por el Camino de Santiago y por los Paisajes de España, entre una gran variedad de contenidos especializados.

Instituto Cesing: Gestión del patrimonio cultural con mas de 14 años http://www.spainsoft.es/CESING/

El instituto Cesing es una compañía nacional con más de 14 años de experiencia en Patrimonio Documental y Cultural. Su actividad en los últimos 14 años se ha centrado principalmente en: inventarios de objetos bibliográficos y artísticos, catalogación de patrimonio documental y cultural, aplicaciones informáticas para la gestión del patrimonio cultural, planificación y reordenación de bibliotecas, informatización de colecciones, estudios de conservación preventiva, restauración, planes de marketing cultural, planes y actividades de difusión, así como actividades de formación.

Los Museos y la Web:

Archives and Museum Informatics

\section{http://www.archimuse.com/}

Conferencias, Publicaciones, Seminarios, Consultas y Búsquedas para los profesionales del patrimonio cultural. Su objetivo principal se centra en la informatización del patrimonio cultural, para lo cuál se celebran encuentros internacionales y se promueven nuevos productos y contenidos de interés en el ámbito de la difusión electrónica en esta disciplina. 


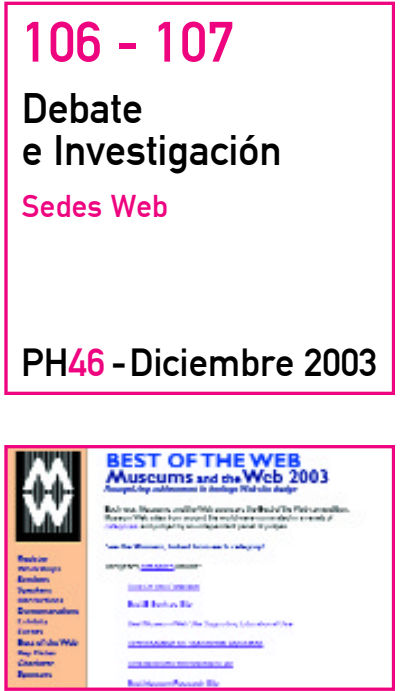

Best of the Web

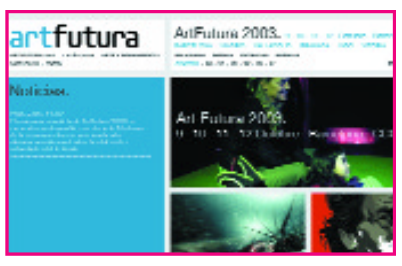

Art Futura



Corridos sin fronteras

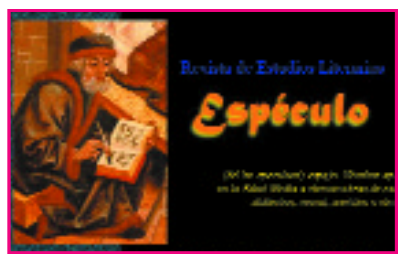

Revista Espéculo

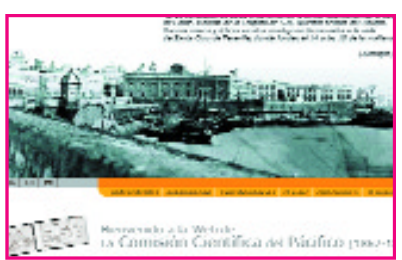

Comisión Científica del Pacífico
Best of the Web: Museums and the Web 2003 http://www.archimuse.com/mw2003/best/ index.html

Cada año, esta sede patrocina la competición "El mejor de la Web". Compiten y se valoran las mejores sedes de Museos de todo el mundo nominadas en diversas categorias, y juzgadas por un grupo de jueces independientes y profesionales del sector.

Las categorías de este año incluyen: Mejor exposición en línea, Mejor sede de Servicios en línea, Mejor sede de Museo con carácter formativo, Mejor aplicación innovadora y experimental, Mejor web de profesionales de museos, Mejor sede de investigación en museos, Mejor visita multimedia de museos.

Nuevas plataformas de expresión artística

Art Futura: la recuperación de la memoria digital http://www.artfutura.org/

Espacio multimedia creado en la década de los noventa con la vocación de servir de plataforma de educación y difusión de nuevas expresiones artísticas. En la sede web que anuncia la celebración de Art Futura 2003 en Barcelona, Madrid, Vigo, Valladolid y Granada y Vitoria, podemos consultar el Programa, las Conferencias, las Exposiciones y las Proyecciones, destacando la retransmisión de las conferencias online mediante Streaming.

Corridos sin Fronteras

http://www.corridos.org/

Dentro del Servicio de Exposiciones del Instituto Smithsonian, se encuentra este producto temático multimedia como una exposición itinerante y una página educativa electrónica que celebra las canciones narrativas conocidas como corridos. Ofrece al interesado la posibilidad de escuchar, aprender y componer el tradicional corrido del nuevo mundo.

Espéculo: revista electrónica de estudios literarios http://www.ucm.es/info/especulo/

Revista digital creada en 1995 en el marco de la Universidad Complutense con el objetivo de transmitir conocimientos literarios en un entorno donde el diseño esté al servicio de una comunicación con fines educativos. La revista se encuentra estructurada en tres secciones: Estudios, Entrevistas y Crítica, reseñas y novedades.

La Comisión Científica del Pacífico (1862-1866) http://www.pacifico.csic.es/

Un viaje virtual para la difusión de una experiencia del patrimonio cultural del CSIC. En homenaje al impulsor de las relaciones culturales y científicas entre España y América Latina durante la segunda mitad del siglo XIX: Jiménez de la Espada.

La Web se ha desarrollado entre 1998 y 2000 , renovándose entre 2002 y 2003. El objetivo del proyecto es establecer un sistema de información que permita el acceso al patrimonio científico y cultural generado por esa expedición científica y que se custodian actualmente en los archivos y colecciones del Museo Nacional de Ciencias Naturales y del Real Jardín Botánico y en la Biblioteca General de Humanidades del CSIC en Madrid, estableciéndose así las bases documentales para la elaboración de productos multimedia que permitan reconstruir las vicisitudes y logros de una empresa científica.
Susana Limón Rodriguez

Centro de Documentación del IAPH 